\title{
INTRODUCTION - MOVING EMOTION FORWARD: FROM THE UBIQUITY OF EMOTION IN MENTAL PROCESSES TO REWINDING ITS ORIGINS
}

\author{
Francisco Esteves ${ }^{1}$ \\ Patricia Arriaga ${ }^{2}$ \\ Augusta Gaspar ${ }^{3}$
}

Emotional phenomena are difficult to investigate, almost by definition. Emotional experience belongs to the sphere of what is inherent to the individual, hard to completely translate into words or behaviour. This subjective tone that characterizes emotions was an argument for those denying it the possibility of scientific scrutiny, during the decades that the behaviouristic approach was the dominant perspective in scientific psychology, and even after the paradigm shift toward cognitive psychology. But since Zajonc's (1980) seminal paper and the debate that followed on the relation between cognition and emotion, a major shift has been taking place. Zajonc's emphasis on the primary importance of emotional processing in our life has become a central issue in psychological research, reflected, for example, in the work of Damásio (1994; 1999), and LeDoux (1996; 2002). As Lazarus puts it "Zajonc had touched a nerve and uncovered an unresolved set of modern issues that apparently had lain dormant in the minds of many psychologists" $(1999$, p. 7).

This special issue covers several current trends in Emotion research. Emotion driving cognitive processing, in contrast to being opposed to it, is clearly stated in three experimental studies in this issue. Also, in more than one paper the authors challenge stimuli submitted to appraisal as being too artificial, emphasizing the influence that spontaneous emotional utterances vs. "coached" ones may have on experimental outcomes. In this second issue of the Special edition on Emotion and Social Behaviour we also present two

\footnotetext{
${ }^{1}$ Instituto Universitário de Lisboa (ISCTE-IUL), Centro de Investigação e Intervenção Social (Cis-IUL), Lisboa, Portugal

${ }^{2}$ Instituto Universitário de Lisboa (ISCTE-IUL), Centro de Investigação e Intervenção Social (Cis-IUL), Lisboa, Portugal

${ }^{3}$ Instituto Universitário de Lisboa (ISCTE-IUL), Centro de Investigação e Intervenção Social (Cis-IUL), Lisboa, Portugal
} 
review papers, both expressing concern with conservative dominant views of emotion - one on the facial expressions of emotion, the other on human empathy's biological roots. An evolutionary perspective of emotion clearly binds both theoretical papers and the experimental paper on responses to food stimuli. New paradigms are suggested in almost all articles.

The review Emoções e Expressão Facial: Novos Desafios [Emotions and Facial Expression: New Challenges] by Sousa, provides an overview of current issues in the study of "facial expressions "and a clear statement of the current inability of the popular view of expressions as stable, predictable, cross-cultural prototypical facial configurations translating underlying discrete emotions to explain spontaneous facial behaviour in real-life emotional events. The term "facial expression" itself has acquired a connotation with "emotion face" sensus "cue to the inner feelings" that has become hard to expunge. Sousa's paper is a reminder that it is ever more relevant to engage in naturalistic and/or experimental studies of emotion in which spontaneous facial behaviour is measured and coded. The author is much inspired by Russell and Fernandez-Dols (1997) ensemble The Psychology of facial expression, a book that gathers many experts in emotional behaviour and the different paradigms they use to study facial behaviour. In this vein, Sousa proposes research based on a variety of theoretical models for which there has been abundant empirical support in recent years: behavioural ecology inspired models, centered on the communication function, and componential models, de-centered by nature, accommodating the contribution of such diverse variables as context, individual traits, ontogenetic stage, emotion and culture.

The ability to tell whether someone is telling lies or the truth is crucial to social interaction and many studies have tried to identify which verbal and non-verbal clues are relevant when efficiently decoding lies. For example, Ekman (1984) in the famous book Telling lies provides some clues, although far less conclusive than "Lie to me" (the popular TV series inspired in the book) tends to make believe. Lie detection is thought to be based on hidden emotional "leakage", "facial action asymmetry" or the "unnatural" timing of facial actions, changes in voice pitch, inconsistencies between body and facial behaviour and so on. Communication theory, framed within Behavioural Ecology, postulates that deceit is a sustainable strategy for as long as there aren't too many deceivers (Trivers, 1985). Most research in this area has shown that people are not accurate at judging lies and truth. To identify predictors of lie detection, most research has focused on a certain group of professionals that work in this field (e.g., law enforcement officers, psychologists). Some attention has also been given to individual traits, but the findings have remained inconclusive. In the paper Haverá Diferenças Individuais na Capacidade para Detectar a Mentira e a Honestidade nos Outros? [Are there Individual Differences in the Ability to Detect Lie and 
Honesty in Others?], Rodrigues and Arriaga elect gender and emotional intelligence as potential individual differences for lie and truth detection. Based on a similar experimental methodology to that used by Edelstein, Luten, Ekman, and Goodman (2006), participants in their study were exposed to short prerecorded interviews with both "liars" and "truth tellers" (people instructed to do so by the researchers) and were then asked to make lie/truth judgments about target statements, as well as to choose which clues they were using when labeling targets as liars. Overall, accuracy rates for detecting lie approached what would be expected by chance. Targets' truthful statements were detected less accurately. However, most participants judged targets as "liars", indicating a possible bias toward detecting lie. Interesting results were found regarding gender differences. Whereas men seemed more accurate at detecting lie (mostly based on verbal clues), women detected truth better, and seemed to be directing attention to more emotional clues when judging lies. Males were also more likely to judge targets as liars. Although these findings indicate that gender differences occurred, no substantial relation between emotional intelligence dimensions was found to be linked to lie and truth detection. The authors discuss several limitations of their work, with an emphasis on the artificial stimuli that were used to gather "liars" and "truth-tellers". Perhaps using spontaneous behaviour as stimuli would make a major difference - a relevant guideline they leave for future research.

In the paper Impacto da Expressão Facial na Percepção de Tempo: Papel da Valência e da Activação [The impact of Facial Expression on Time Perception: The role of Valence and Arousal], Fernandes and Garcia-Marques report a study on the effect of stimulus emotional valence - emotionally loaded stimuli like facial expressions - and arousal on time perception. The old notion, repeatedly confirmed, that emotion interferes with our subjective experience of time, creating an impression that emotional events/stimuli last longer than non-emotional ones, is at the basis of this line of research. But the complexities of studying the temporal effects of stimuli properties are enormous, as many studies, which the authors review, have provided contradictory reports on both arousal and valence. Considering studies that report negative stimuli to significantly recruit more attention than other stimuli, the authors hypothesized that angry faces would be perceived as lasting longer than happy faces, which they confirmed, but they also envisage a moderating effect of exposure time and intensity of the facial expression, and found that this interaction has further intricacies, as attentional processes and induced arousal seem to be playing relevant roles as well.

In Esteves, Arriaga, Carneiro, and Flykt's paper Psychophysiological and Psychological Responses to Pictures of Food Stimuli, several paradigms to assess emotional responses were used, each with a specific goal. One such 
paradigm is emotional induction, another is backward masking. In the latter, emotional stimuli are presented subliminally and masked by another (neutral) stimulus, so that the participant is unaware of the target stimulus and the emotional response can be ascertained to pre-attentive processing. Both verbal and physiological responses (skin conductance and heart rate) were measured to analyse emotional responses. Authors departed from decades of accumulated evidence that emotionwise not all stimuli are the same, and for some (e.g. snakes) extinguishing a fear response is much harder than for others (e.g. guns) because the emotional reaction to that stimulus has been in the first case hardwired by millions of years of stimulus-response co-evolution (for a review see Öhman, 2000; Öhman \& Mineka, 2001). Within this framework, food stimuli are likely to be strong emotion elicitors, as kinds of food are also distinct from an evolutionary perspective and thus from their relevance and preference (e.g. almost all mammals, and all primates in particular, show great preference for highly caloric food, which often have a sweet taste, and are not easily available year round in a hunter-gatherer context). As the paper indicates, ontogeny plays a role in specifying food preferences as reactions are not as hardwired to specific food items as they are to specific phobic animals. In a series of four experiments, recruiting the aforementioned methods, the authors compared female participants with unhealthy attitudes toward food, dieting and body shape, to a control group in their responses to pictures of low and of high caloric foods, and other emotional stimuli. Overall, verbal and physiological responses to food stimuli did not differ from those toward other emotion relevant stimuli. The two food categories were not distinguished in the basis of response, although "food-worried" participants showed larger skin conductance responses than the control group in response to food pictures. Food stimuli, the authors concluded, are by no means subjected to the same processing as unconditioned fear stimuli, even for individuals who are especially concerned about eating lean low caloric food. But some questions remain open, as for example pictures of food and real food may be very distinct elicitors. Also relevant, the group of participants that expressed higher levels of worries regarding food was not recruited from a clinical population with eating disorders. The study is promising for future clinical research, as for people with serious food disorders. Further investigation on the reactions to food stimuli, and the possibility of reconditioning, may bring new hopes for treatment.

In the paper Os Preditores Emocionais e Sociais da Aceitação pelos Pares em Crianças de Idade Escolar [Emotional and Social Predictors of Peer Acceptance], Alves and Cruz report a cross-sectional study in which children's emotional knowledge, social skills and peer acceptance were studied. The authors frame their work within the Social Information Processing Model and hypothesise that social skills mediate the relation between emo- 
tional knowledge and peer acceptance, on the rational that people who are more knowledgeable of emotional expressions and emotion eliciting contexts will interpret their interpersonal behaviour more appropriately, and thus engage in more positive social interactions. Gender differences were also analysed. Measures of children's emotional knowledge were obtained during structured interviews in which several scales were used. Measures of social skills were based on teachers' ratings, and the peer acceptance was assessed from children's peer nominations. The authors found that girls were rated as being more skilled in cooperation than boys, a finding that has been replicated across surveys. There were no other significant gender differences. But most relevant, their results supported the fact that emotional knowledge predicts social skills, which in turn predict peer acceptance. Taking these findings into account, the authors propose educational strategies oriented towards the promotion of pro-social behaviour, which they believe to be largely supported by emotional knowledge.

Another highly consensual stepping stone of prosocial behaviour is another emotional phenomenon - empathy, which varies across individuals as well as across ages during development and, as becomes salient from reading the previous article, across species as well. The closing paper by Castro, Gaspar and Vicente, The Evolving Empathy: Hardwired Bases of Human and Non-human Primate Empathy, is a provocative incursion into the sacred realm of beliefs people hold on their relation to the rest of the animal kingdom - that empathy is a building block of human nature - something that we think we have and that other animals don't. In this review of literature supporting the existence of empathy in non-human primates, the authors build a case for the evolutionary roots of empathy - listing evidence of its neurological basis, evoking behavioral evidence, and reasoning about its sense in terms of evolutionary fitness. A clear support is given to Preston and De Waal's (2002) Perception-Action Model of Empathy, by structuring examples of empathy in primates into the degrees of complexity, conscientiousness and automaticity envisaged by the model. Great emphasis is put on the role of the discovery of Mirror Neurons and a Mirror Neuron System (e.g. Gallese, 2001; Iacoboni, 2009; Rizollati et al., 2004), and on the more recent discoveries of specific neuron populations that mirror specific emotional reactions (e.g. disgust, joy) in materializing the processes and the physical underpinnings of empathic behavioural responses.

Finally, we wish to express our gratitude to our contributors and reviewers, who made this volume an important contribution to the broad field of Emotion and Social Behaviour. Highly relevant and interesting questions were raised, distinct approaches and paradigms were used, and suggestions for future research were outlined. It is our hope that theory and research on Emotion and Social Behaviour will continue to move forward into a better understanding of the role that emotion plays in our lives. 


\section{References}

Damásio, A. (1994). Descartes error. New York: Putman.

Damásio, A. (1999). The feeling of what happens. London: William Heinemann.

Edelstein, R. S., Goodman, G. S., Ekman, P., \& Luten, T. L. (2006). Detecting lies in children and adults. Law and Human Behaviour, 30, 1-10.

Ekman, P. (1985). Telling lies: Clues to deceit in the marketplace, politics, and marriage. New York, NY: W. W. Norton.

Gallese, V. (2001). The 'Shared Manifold' hypothesis: From mirror neurons to empathy. Journal of Consciousness Studies, 8, 33-50.

Iacoboni, M. (2009). Imitation, empathy, and mirror neurons. Annual Review of Psychology, 60, 653-670.

Lazarus, R. S. (1999). The cognition-emotion debate: A bit of history. In T. Dalgleish \& M. J. Power (Eds.), Handbook of cognition and emotion (pp. 3-19). New York: John Wiley \& Sons.

LeDoux, J. (1996). The emotional brain. New York: Simon \& Schuster.

LeDoux, J. (2002). Synaptic self: How our brains become who we are. New York: Viking Press.

Öhman, A. (2000). Fear and anxiety: Evolutionary, cognitive and clinical perspectives. In M. Lewis \& J. M. Havilland (Eds.), Handbook of emotions ( $2^{\text {nd }}$ ed., pp. 573-593). New York: Guilford Press.

Öhman, A., \& Mineka, S. (2001). Fears, phobias, and preparedness: Towards an evolved module of fear and fear learning. Psychological Review, 108, 483-522.

Preston, S. D., \& de Waal, F. B. M. (2002). Empathy: Its ultimate and proximate bases. Behavioral and Brain Sciences, 25, 1-71.

Rizzolatti, G., \& Craighero. L. (2004). The mirror-neuron system. Annual Review of Neuroscience, 27, 169-192.

Russell, J. A., \& Fernandez-Dols, J. M. (1997). The psychology of facial expression. New York: Cambridge University Press.

Trivers, R. (1985). Social evolution. Menlo Park, CA: Benjamin Cummings.

Zajonc, R. B. (1980). Feeling and thinking: Preferences need no inferences. American Psychologist, 35, 151-175. 